\title{
A importância do afeto na conduta do Médico de Família e Comunidade
}

\author{
The importance of affection in the conduct of the Family Physician
}

\section{La importancia del afecto en la conducta del Médico de familia y Comunidad}

José Mauro Ceratti Lopes. Grupo Hospitalar Conceição (GHC). jmauro.lopes@terra.com.br (Autor correspondente)

Lêda Chaves Dias Curra. Grupo Hospitalar Conceição (GHC). leda.curra@terra.com.br

\section{Resumo}

0 texto trata da utilização do afeto como ferramenta essencial na relação clínica que se estabelece na prática entre o Médico de Família e Comunidade (MFC) e as pessoas sob seus cuidados. Relação diferente do que acontece em outros cenários de prestação de cuidados à saúde. Entender o processo desta relação, identificar a troca de emoções que nela acontece, reconhecer as reações e dificuldades de forma consciente, torna o desfecho favorável, melhorando 0 cuidado prestado e a satisfação.

\section{Abstract}

This paper addresses the use of affection as an essential tool in the clinical relationship that is established, in practice, between family physicians (MFC) and their patients. This relationship is different from those of other health care scenarios. Understanding the process of this relationship, identifying the exchange of emotions, acknowledging the reactions and difficulties consciously, contributes to a favorable outcome, improving the care provided and the satisfaction of both.

\section{Resumen}

Este texto trata del uso del afecto como herramienta esencial en la relación clínica que se establece en la práctica entre el Médico de Familia y Comunidad y las personas a su cargo. Es diferente de lo que sucede en otros escenarios de prestación de servicios de salud. Comprender el proceso de esta relación, identificar el intercambio de emociones que en ella se establece, reconocer conscientemente las reacciones y las dificultades hace que el resultado sea favorable, mejorando la atención ofrecida y la satisfacción de ambos.

\section{Palavras-chave: \\ Afeto \\ Médicos de Família Referência e Consulta Atenção Primária à Saúde}

\section{Keywords:}

Affection Family Physicians Referral and Consultation Primary Health Care

\section{Palabras clave:}

Afecto

Médicos de Familia Remisión y Consulta Atención Primaria de la Salud 
sm. Disposição de alma, sentimento. / Amizade, simpatia: nutria por mim um grande afeto. / Psicologia: Aquilo que age sobre um ser: a sensação é um afeto elementar.

Cabe falar um pouco sobre o porquê de estarmos escrevendo a quatro mãos este texto. Na história da humanidade a associação em duplas tem sido uma constante. Podemos começar com Adão e Eva, passando por outras como Dom Quixote e Sancho Pança, Bonnie e Clyde, o Gordo e o Magro, Fred e Barney, Batman e Robin, Jerry Lewis e Dean Martin, Felipão e Murtosa, entre tantas outras. Assim consegue-se somar conhecimentos, ter cumplicidade ao produzir, ter apoio, confiança e há estimulo à criatividade. No trabalho a dois necessita-se respeitar um ao outro, saber negociar, e consequentemente há troca de sentimentos e emoçóes. A dupla é uma pequena equipe que se une para produzir e superar desafios. E duplas também têm a ver com o tema, pois para superar os desafios de cuidar da saúde é necessário que se forme uma, composta pelo médico e pela pessoa. É claro, sem esquecer o restante do contexto, tendo em vista que o cuidado da saúde é um fenômeno integrativo, assim como saúde também o é (Quadro 1).

Quadro 1. Saúde como fenômeno integrativo².

- Os determinantes de saúde e doença não são apenas biológicos, nem tampouco uma resposta das pessoas aos agravos ou doenças;

- Pessoas vivem em famílias e comunidades de vários tipos. Frequentemente trabalham em ocupações insalubres ou mesmo perigosas e têm como lazer atividades que podem promover ou não a saúde; e

- Pessoas vivem dentro de um grande contexto ambiental, político e cultural que afeta a elas e também a suas famílias e comunidades. Todos esses aspectos "pouco biológicos" da vida das pessoas influenciam seu estado de saúde ou condição de doença.

O cuidado da saúde moderno é "a mais complexa atividade nunca desenvolvida pelo ser humano"2. Ele envolve tecnologia altamente complicada, que pode causar sérios danos ou curar milagrosamente. É uma atividade em equipe, com mais de $80 \%$ dos cuidados prestados por não médicos, e essa interação complexa e multifacetada precisa ser orquestrada ${ }^{2}$. Mas apesar de todo o progresso e desenvolvimento, o evento central da vida profissional do médico de família e comunidade continua sendo a consulta. Na relação entre pessoas, o sentimento de afeição entre elas pode ser "à primeira vista", "apaixonante" ou seguir um caminho de construção através do conhecimento progressivo mútuo, continuado, onde se estabelece uma relação baseada na confiança.

A relação médico-pessoa, que é sistêmica e processual, também é um encontro entre pessoas com expectativas, objetivos e tarefas definidas de parte a parte. O preparo para este encontro inicia-se bem antes. Para o médico, começa (a) com sua trajetória pessoal e atuação no curso de graduação (se não estiver preocupado apenas com doenças e diagnósticos); segue com (b) a escolha da especialidade; (c) com o preparo na especialização; (d) tem relação com o seu momento de vida; e culmina (e) com os momentos preliminares à consulta. Para a pessoa, começa (a) com o estabelecimento do estilo de vida, heranças e outros aspectos biopsicossociais que interferem na saúde; segue (b) com a decisão de consultar - muitas vezes não é ele quem decide; (c) depois vem a escolha do médico; (d) tem um momento decisivo na recepção do consultório; e (e) seu preparo final na sala de espera. Para ambos, toda essa preparaçáo tem seu clímax (f) na consulta, pois quando essas duas pessoas se encontram temos dois experts: o médico em diagnósticos, exames e medicamentos; e a pessoa nela própria ${ }^{3}$. Mas náo se encerra aqui, pois ainda temos: $(\mathrm{g})$ os exames a fazer, $(\mathrm{h})$ o atendimento em equipe, (i) o contato com a família e as (j) consultorias, onde a participação do médico de família como orquestrador desses cuidados é necessária.

Muitas vezes a empatia é imediata e ocorre já no primeiro encontro. Em outras, em virtude das expectativas, ansiedades, defesas, experiências anteriores e medos de ambas as partes, o primeiro encontro pode náo ser muito bom. Em ambos os casos, a continuidade da relação pode mudar e muitas vezes inverter essa primeira impressão. Devemos dar a nós e à pessoa uma segunda chance.

O elemento chave para alcançar êxito nesse encontro é preservar e melhorar a relação médico-pessoa, fundamental para o sucesso do diagnóstico e tratamento, pois o processo de interaçáo entre médico e pessoa é possivelmente o aspecto mais terapêutico do encontro para cuidar da saúde ${ }^{4}$.

A consulta, independentemente do cenário em que ocorre - consultório, hospital, domicílio - é a parte fundamental do relacionamento entre o médico e as pessoas. Hipócrates exerceu a medicina inteiramente voltada para o doente, interessado 
pelo sofrimento do homem, examinava as pessoas de forma cuidadosa e conversava com elas sobre suas queixas, denotando o quanto valorizava a relação clínica. Foi ele o primeiro a nortear os preceitos da ética e dessa relação com citaçóes objetivas:

O médico deverá saber calar-se no momento oportuno [...] deverá manter uma fisionomia serena e calma e nunca estar de mau humor [...] Deverá dar toda a atenção à pessoa, responder calmamente às objeçôes, não perder a tolerância e manter a serenidade diante das dificuldades (Rezende apud Lopes ${ }^{5}$ ).

A imagem que vem à cabeça ao lermos essa descrição é a de um "médico Mona Lisa”. Hoje, devemos levar em conta os escritos de Hipócrates, mas o profissional pode e deve ser mais interativo e, como disse um colega anônimo, "pode até chorar com a pessoa; só não deve chorar mais que a pessoa". Existe uma série de atitudes que podem ser empregadas para melhorar a efetividade do encontro do médico com as pessoas ${ }^{6}$. A consulta é distinta por diversas qualidades:

- A pessoa toma decisóes com o seu médico e portanto a comunicação efetiva entre o médico de família e a pessoa é uma das chaves do sucesso.

- A medicina é centrada na pessoa, sendo que o contexto familiar e social deve ser amplamente conhecido.

- Frequentemente, a relação entre o médico de família e a pessoa é mantida durante anos e a sua abordagem é o resultado da construção ocorrida.

Tradicionalmente, a sociedade autoriza o médico a tomar decisões e ter o poder e a autoridade a respeito das necessidades da pessoa. Ela, por sua vez, é encorajada a dar a responsabilidade ao médico e permanecer no papel de doente (ou dependente), pelo menos temporariamente. Há que se dosar esse poder chegando a um equilíbrio que possa auxiliar a pessoa doente. Algumas vezes, quando a pessoa está agudamente e seriamente enferma, o médico necessita assumir a responsabilidade sobre o seu cuidado; entretanto, deve-se compreender que a consulta é um encontro entre dois indivíduos, onde cada um é um expert na sua própria área: o médico de família é um expert no cuidado que envolve diagnosticar e tratar adequadamente. Seu aparelho diagnóstico principal é o auditivo - ESCUTAR! -, pois dois minutos sem interrupção são suficientes para a pessoa colocar as questôes principais, onde o principal "medicamento" é o INTERESSE pelas pessoas e seus problemas de saúde (não pelas doenças) ${ }^{3}$. As pessoas são experts em trazer a informação e experiência com as quais a consulta se desenvolve ${ }^{3}$.

Para a consulta ser bem-sucedida, o médico e a pessoa devem trabalhar juntos e acordar, dividindo informaçôes a respeito das possibilidades e consequências ${ }^{3}$. Tornam-se "sócios", parceiros, e para que haja parceria em medicina o sócio principal tem de ser a pessoa, que não deve ser impedida de pronunciar a palavra decisiva, a última palavra ${ }^{3}$.

Embora existam muitas facetas na prática do médico de família e comunidade, a abordagem aqui proposta refere-se à importância do afeto na conduta do médico, pois muitas vezes o problema não está na pessoa e sim entre as pessoas. Daí surgiu a seguinte questão: o que, na relação médico-pessoa, faz diferença, faz a pessoa sentir-se melhor e aderir ao cuidado? Partilhamos a ideia de que é a afetividade na relação.

O Dr. Carlos Grossmann ${ }^{5}$, criador do Serviço de Saúde Comunitária em Porto Alegre, sempre conceitua o médico de família da seguinte forma: "É um especialista em gente [...]! - as pessoas, as famílias, as comunidades na sua visão e abordagem mais amplas e integrais - e acrescentaríamos [...] Médico de família é quem gosta de gente!"5

A construção de um vínculo que ao mesmo tempo seja técnico, porém onde haja a cumplicidade de afeto, implica em desenvolver habilidades apropriadas, ter embasamento teórico e fundamentar-se nas necessidades e experiências individuais.

O médico de família tem aspectos característicos em sua prática que facilitam o desenvolvimento e fortalecem esse vínculo e que o diferenciam dos demais especialistas. Dois desses sáo essenciais: a diversidade da demanda e a responsabilidade. A diversidade é caracterizada pela variedade de problemas que as pessoas trazem ao médico de família e comunidade. Num primeiro momento é ansiogênica, gerando stress e insegurança. Com o passar do tempo, o MFC, ao introjetar o uso das ferramentas da prática, assume o controle e essa situação adversa transforma-se em desafios do dia a dia. Soma-se a isso o prazer de trabalhar na busca de soluçóes conjuntas com as pessoas atendidas, que o valorizam como parceiro. Esse desafio constante e o vínculo interpessoal mantém o MFC profissionalmente estimulado e vinculado à APS. A responsabilidade se relaciona ao papel essencial da prática do MFC em assumir a responsabilidade pela coordenaçáo do cuidado ${ }^{6}$ das pessoas sob seus cuidados, decorrente de ser quem tem a qualificaçáo clínica mais ampla e detêm maior conhecimento sobre aquela pessoa, especificamente. A partir do momento em que o MFC aceita a responsabilidade pelo cuidado de uma pessoa. isso se torna total e permanente até que decidam o contrário. Essa responsabilidade vai além do foco individual e inclui recomendar e defender políticas públicas de promoção da saúde para as pessoas e comunidades. É uma responsabilidade 
contínua, independendo da condição de saúde em que se encontram as pessoas, não existindo um início ou fim, podendo o contato ser retomado a qualquer momento de necessidade ou por diferentes problemas ${ }^{6}$.

Junto a esses cuidados existem outros, tais como foco da prática (o MFC é focal na pessoa), continuidade dos cuidados (longitudinalidade), estilo diagnóstico (geração de hipóteses diagnósticas e testes), classificaçáo diagnóstica (ICPH2), história natural das doenças (problemas indiferenciados, no início, ou pouco definidos).

Essas características da prática do médico de família somente terão validade se estiverem associadas a um princípio básico, fundamental e imprescindível - o médico de família deve ser qualificado:

- na resolutividade ("o $\operatorname{Dr}(\mathrm{a})$. acerta comigo");

- na responsabilidade (nunca diz "seu caso não é para mim");

- no conbecimento da pessoa ao longo do tempo (médicos de família conhecem as pessoas antes de saberem que doenças vão ter);

- e no reconhecimento de seus próprios limites (utilizando os recursos da equipe e do sistema de saúde na busca do melhor cuidado).

É conhecido que diversas orientaçôes (Quadro 2) podem ser utilizadas pelo médico em seu comportamento para permitir o melhor acesso à consulta ${ }^{6}$.

Quadro 2. Orientações para melhor acesso à consulta ${ }^{6}$.

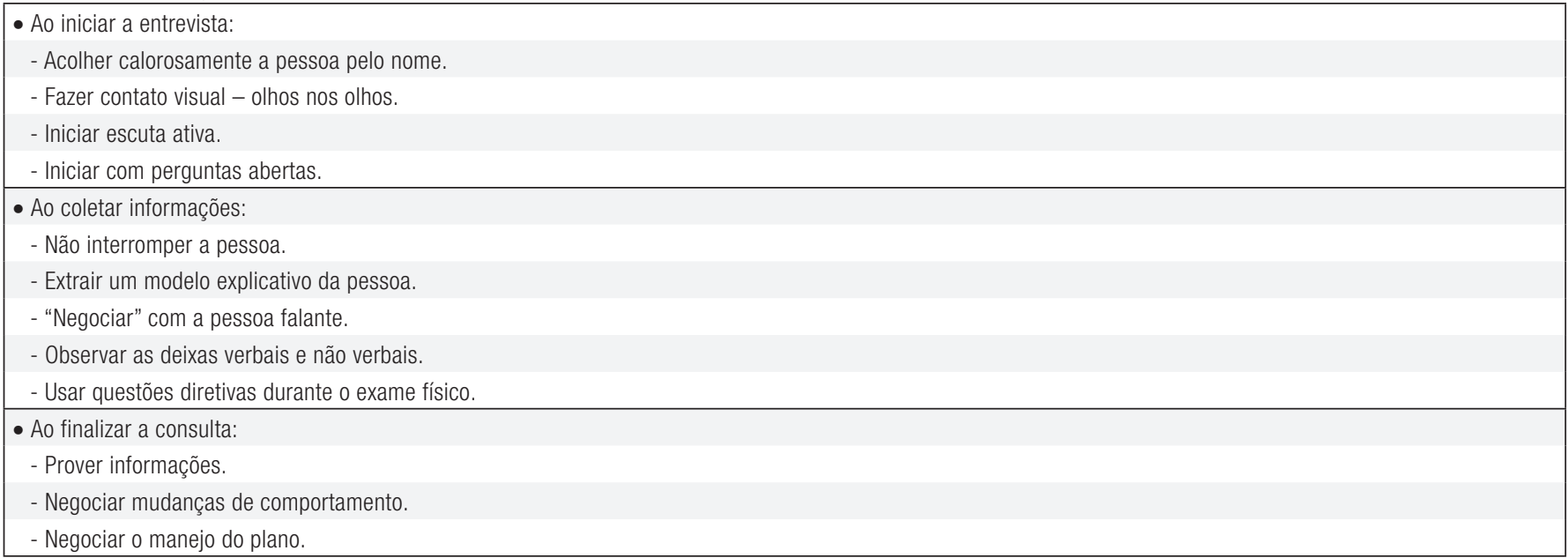

\section{Segundo Mário Moura:}

[...] o médico começa a fazer "significar" ao abordar. Dar o salto para o lado de lá do sintoma e detectar o simbolismo da cefaleia, da cólica, da dor precordial, da asma, do eczema e de quantas coisas mais que traduzem a maneira de o doente nos trazer a sua angústia, pelos problemas que vive ou viveu, que surgem com força como causas verdadeiras de doenças ${ }^{7}$.

O médico de família deve transcender a divisão corpo/mente, para o que a atenção às emoções é uma necessidade, pois ele precisa não somente decodificar mensagens da pessoa mas ser muito receptivo àquelas informaçôes que indicam em que contexto as mensagens estáo codificadas ${ }^{8}$. A percepção da pessoa deve vir através de reconhecimento de posturas, gestos, expressốes verbais ou não verbais.

Uma vez percebida a pessoa, inicia-se então a comunicação não verbal, uma relação emocional entre duas pessoas até atingir seus sentimentos mais genuínos e profundos. 
Moura ainda reflete:

Como medicamento, o médico tem uma dosagem apropriada, poderá ter excessos ou carências de dose, poderá provocar às vezes reaçôes de intolerância. A importância desta "terapêutica" é, talvez hoje, maior do que nunca... sobretudo com o resultado do incremento da vida urbana, em que um significativo número de pessoas perdeu as raízes e os apoios; famílias grandes com interrelaçóes íntimas e complexas tendem a desaparecer e o indivíduo torna-se cada vez mais solitário, até encontrar-se completamente só.

Do outro lado, como existe o médico, que é a outra parte da relação, é inevitável pensarmos em como vai sua disponibilidade e disposição? Quais são suas concepções? Seu desejo de empatia? De que tempo dispõe? Que pressão sofre da demanda que o espera para atendimento? Como vai a sua vida pessoal? Como vai a sua formação contínua, seu estudo e o seu trabalho? Qual a recordação de experiência passada idêntica à que tem na sua frente ${ }^{8}$ ? Ou seja, é fundamental cruzar os aspectos subjetivos do médico e da pessoa para que ambos comecem a sentir a atuação mais humanizada, com o reconhecimento das emoçôes e uma prática autorreflexiva?.

O médico de família também precisa levar em conta que ao cuidar de integrantes de uma família torna-se parte desse complexo de relacionamentos, acrescido pelo fato de que alguns MFCs compartilham com as pessoas a mesma comunidade como local de residência.

O diagnóstico sob a óptica relacional é o resultado de contínuas mudanças9. O médico de família sofre constante influência pelas emoçóes vivenciadas, que nos fazem sentir, refletir e mudar ou não de opinião. As pessoas só vão encontrar respostas aos seus apelos se "nos permitirmos nos aproximar"... e então é através do afeto que poderemos dar respostas.

O médico de tempos atrás contava com seus conhecimentos e equipamentos que cabiam em sua maleta. Eram ele e a pessoa. Hoje, existe a tecnologia, uma parafernália sem fim, e existem os gestores como intermediários na relação.

Mas, ao final das contas, para que tudo isto funcione e seja corretamente aproveitado, o principal continua sendo o mesmo: uma relação de confiança, humanitária e com muito afeto entre médico e pessoa.

\section{Referências}

1. Ferreira ABH. Dicionário On line. [acesso em 2013 Jan 16]. Disponível em: http://www.dicionariodoaurelio.com/Afeto.html

2. Coulter A. After Bristol: putting patients at the centre. BMJ. 2002; 324(7338): 648-51. PMid:11895824 PMCid:84404. http://dx.doi.org/10.1136/ bmj.324.7338.648

3. Lown B. A Arte Perdida de Curar. São Paulo: JSN Editora Ltda; 1997. PMCid:508096.

4. Stewart M. Medicina Centrada na Pessoa. Porto Alegre: Artmed; 2010.

5. Lopes JMC. A pessoa como centro do cuidado: a abordagem centrada na pessoa no processo de produção do cuidado médico em Serviço de Atenção Primária à Saúde. [Dissertação]. Porto Alegre: Universidade Federal do Rio Grande do Sul; 2005. Disponível em: http://hdl.handle.net/10183/5873

6. Stephenson A. Textbook Of General Practice. 1th ed. 246 London: Arnold; 1998.

7. Moura MS. A trajectória do amor: ensaio sobre a medicina familiar. Execução gráfica Corlito, Setúbal; 2000.

8. Rakel. Textbook of Family Medicine. 8th Ed. Philadelphia: Elsevier Saunders; 2011.

9. McWhinney I. Manual de Medicina de Família e Comunidade. Porto Alegre: Artmed; 2010.

\section{Leitura Recomendada}

1. Fowler G, Gray MJA, Anderson P. Prevention in general practice. 2nd ed. Oxford and New York: Oxford University Press; 1993.

2. Andolfi M. A linguagem do encontro terapêutico. Porto Alegre: Artes Médicas; 1996.

3. Jenkins L, Britten N, Barber N, Bradley CP, Stevenson FA. Consultations do not have to be longer. BMJ. 2002; 325(7360): 388. PMid:12183315 PMCid:1123894. http://dx.doi.org/10.1136/bmj.325.7360.388

4. Gusso G, Lopes JMC. Tratado de medicina de família e comunidade. 1. ed. Porto Alegre: Artmed; 2012. 